\section{Come and experience the difference yourself}

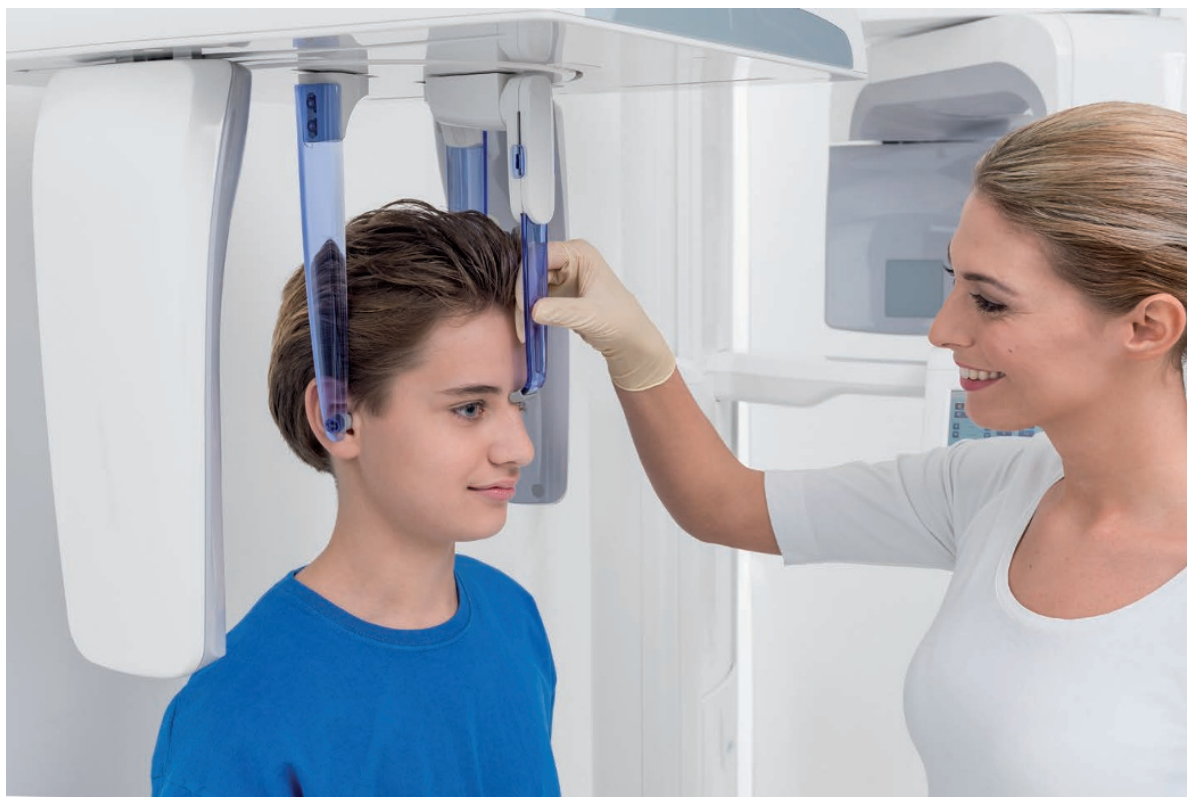

Dürr Dental will be exhibiting a range of their equipment at this year's BDIA Dental Showcase. Their brand is synonymous with leading edge imaging equipment. Their panoramic device is so easy to use you won't need a second take, as the first one will almost certainly be perfect. Unlike other devices this unit does not rely on experience or expertise, in fact both are almost negligible. Come and experience the difference yourself. You'll also get a chance to experiment with a totally new piece of imaging equipment!
Visitors might also be interested in the latest networking systems that can be used linking them to the network, practices can see the performance of each piece of equipment at a glance. Linking the compressor, for example, to the digital network yields numerous benefits: current status, faults or messages, such as for filter changes, are immediately displayed.

Visit Dürr Dental on stand D30. with your compressor and suction system. By

\title{
Game-changing restorative solutions
}

VOCO would like to welcome Dental Showcase visitors to stand M26 to meet their knowledgeable team of experts who'll be on hand to offer advice on all aspects of restorative, preventive and minimally invasive dentistry.

With dentistry rapidly moving into the digital realm, VOCO are excited to introduce their SolFlex 3D printer range, which allows users to benefit from the efficiency, accuracy and predictability of digital designs throughout the production stage.

Visitors to the stand will also get to discover VOCO's new Grandio blocs, guaranteeing outstanding aesthetic results and meeting the highest demands of same-day chairside CAD/CAM restorations. Indicated for crowns, inlays, onlays, veneers and implant-supported crowns, Grandio blocs are the strongest in their class, with a superior biaxial flexural material strength of $333 \mathrm{MPa}$ and the highest filler content of any bloc on the market today at $86 \%$.

Plus, there'll be a few VOCO favourites on stand too, including the light-curing, radiopaque Admira Fusion, showing the lowest level of polymerisation shrinkage ( $1.25 \%$ by volume), as well as Profluorid Varnish, containing 5\% sodium fluoride $(22,600 \mathrm{ppm}$ fluoride) to protect teeth against acid attack, promote remineralisation and contribute to the formation of fluorapatite.

Visit VOCO on stand M26 to hear about special show offers and a chance to see our products in action. Alternatively, if you are unable to attend call the expert VOCO team today free on 0080044444555 or email service@voco.de.

\section{Speed and simplicity}

Offering an array of digital, restorative and prosthodontic products, 3M Oral Care will demonstrate its latest solutions at BDIA Dental Showcase.

Find out more about the Filtek One Bulk Fill Restorative with enhanced aesthetics, excellent handling properties and high radiopacity.

Also on display will be the True Definition Scanner, designed to give you the flexibility and accuracy you need for reliable diagnostics.

Discover for yourself how innovative solutions from 3M Oral Care could help you create restorations with speed and simplicity. Don't miss the team on stands G25 and G30 at Dental Showcase.

For more information, call 08456025094 or visit www.3Mespe.co.uk.

$3 \mathrm{M}$ and True Definition are trademarks of the $3 \mathrm{M}$ Company.

\section{Providing an array of cutting- edge technologies}

Dedicated to making your life easier, Carestream Dental provides an array of cutting-edge technologies and equipment to suit the needs of every dental practice.

To discover the latest from the company, meet the team and get involved, visit stands J58 and $\mathrm{K} 60$ at BDIA Dental Showcase this October.

For everyone looking to better understand the practice workflow with Carestream Dental technologies and to find out how its potential can be optimised, a dedicated virtual reality experience will be available. You can also get hands-on with the CS 3600 intraoral scanner by trying it for yourself on-stand.

Further still, all Denplan practices will have the perfect opportunity to find out more about the innovative DEPPA and CS R4+ integration, which afford various time-saving and efficiency benefits for both practice and patient.

To make your life easier, don't miss Carestream Dental at the BDIA Dental Showcase this October. For more information contact Carestream Dental on 08001699692 or visit www. carestreamdental.co.uk. 